\title{
The Symbiosis of Science and Poetry
}

\section{SYLVIAVARDELL AND JANET WONG}

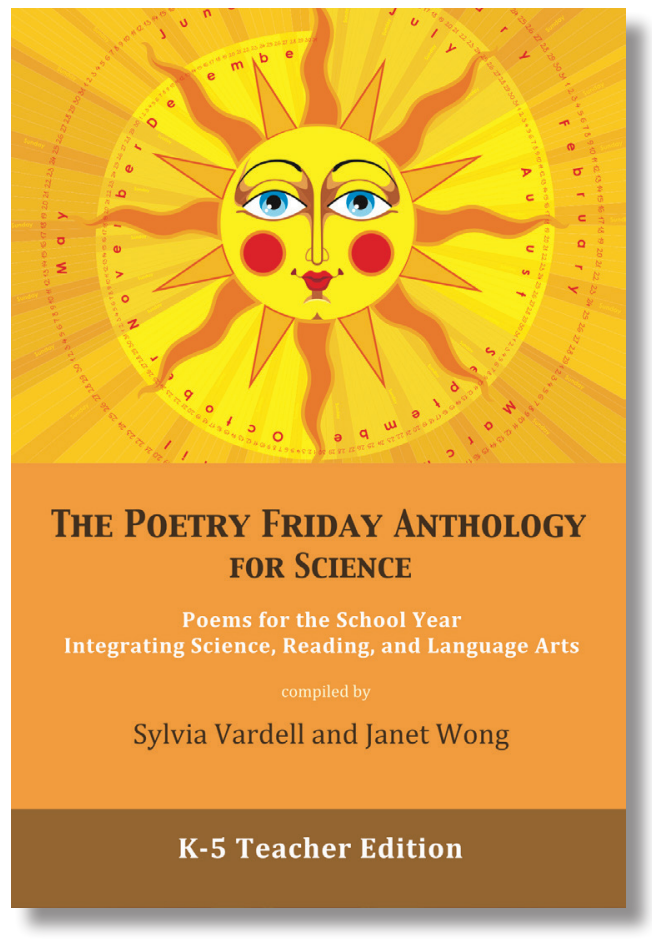

$\mathrm{S}$ ometimes unlikely partners can benefit each other in surprising ways. For example, dogs offer protection and companionship to humans, who in turn provide food and shelter for dogs. This "give-and-take" relationship is called symbiosis, referring to relationships that have mutual benefit.

That's true for the disciplines of science and poetry, too. Science is rich in content and poetry offers powerful language; together they can both inform and inspire.

For some of us, however, science is a little intimidating because of the unfamiliar vocabulary, abstract concepts, and the textheavy format of many science books. But people who feel uncomfortable with science often feel very comfortable with language arts, so a poem might be the perfect way to introduce a science topic.

\section{Experts Agree}

The librarian who wants to plug science during recreational reading time or promote poetry in a science class has the ammunition needed to make a case for either approach. In her 2002 article, Valarie Akerson reminds us that the "processes of science and literacy learning are similar and may help the development of each discipline." ${ }^{1}$

She goes on to observe that the "use of language arts to promote literacy and support learning in other content areas is (also) recommended and encouraged by the International Reading Association (IRA) and the National Council of Teachers of English (NCTE)."2

Literacy expert Timothy Rasinski confirms that poetry can provide practice for oral language development as well as serve as

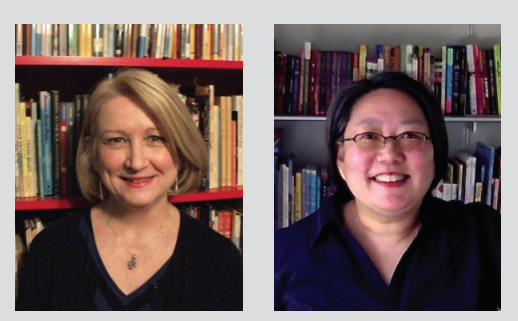

Sylvia Vardell is professor in the School of Library and Information Studies at Texas Woman's University. She has published extensively, including five books on literature for children and more than one hundred journal articles. Her current work focuses on poetry for children, including a regular blog, PoetryforChildren. She is also the Everyday Poetry columnist for ALA's Book Links magazine and the 2014 recipient of the ALA Scholastic Library Publishing Award. Janet Wong is a graduate of Yale Law School and former lawyer who switched careers and became a children's poet. Her dramatic career change has been featured on The Oprah Winfrey Show, CNN's Paula Zahn Show, and Radical Sabbatical. She is the author of thirty books for children and teens. Together, Vardell and Wong are the creative forces behind The Poetry Friday Anthology series, launched in 2012 and adopted by hundreds of school districts nationwide. 
a bridge to understanding content. ${ }^{3}$ Fluent reading enables students to spend less time on decoding and have greater comprehension of the text, according to John Pikulski and David Chard. ${ }^{4}$

Science experts also support a multidisciplinary approach. Jill Castek recommends "breaking down those instructional silos" (of science and literacy) to maximize overlap, ensuring that vocabulary exposure is occurring in many contexts for maximum scaffolding. ${ }^{5}$ Royce, Morgan, and Ansberry confirm "studies have shown gains in literacy as well as science achievement in programs that blend science and literacy instruction." ${ }^{6}$ And in a 2013 Popular Science article, Erin Biba reminds us that the critical thinking and active investigation involved in science can "benefit even students who pursue nonscientific careers ... [since] Everyone is a science consumer."7

\section{Finding Science Poetry}

There are many wonderful sciencethemed works of poetry to choose about animals, weather, seasons, and space. In addition to short, visually appealing poetry collections such as Water Sings Blue: Ocean Poems by Kate Coombs, Ubiquitous: Celebrating Nature's Survivors by Joyce Sidman, and A Strange Place to Call Home: The World's Most Dangerous Habitats and the Animals That Call Them Home by Marilyn Singer, you can also find

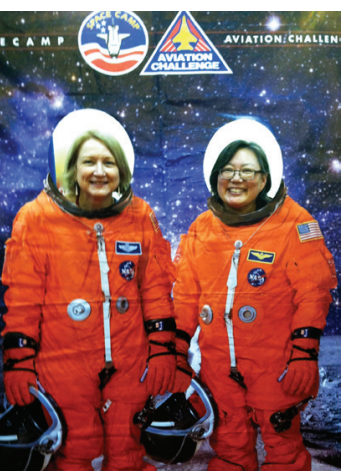
comprehensive anthologies such as

The Tree That Time Built: A Celebration of Nature, Science, and Imagination compiled by Mary Ann Hoberman and Linda Wilson; The National Geographic Book of Animal Poetry compiled by J. Patrick Lewis; and our own The Poetry Friday Anthology for Science, a recent "NSTA Recommends" title endorsed by the National Science Teachers Association. It features 218 poems about solar power and hybrid cars, gears and robots, hurricanes and the human body, video games and glaciers, famous scientists and everyday inventions, and more (along with learning activities for every poem). Using these science poetry resources and many others, it's possible to find a short "poem match" for almost any elementary science topic to provide a moment of learning that is also a fun break in the routine.

One helpful selection resource is the annual list of Outstanding Science Trade Books for Students K-12, cosponsored by the Children's Book Council and the National Science Teachers Association. This annotated bibliography typically includes a few new books of science-themed poetry every year, sometimes in the form of rhyming picture books and verse novels.

In addition, many children's science-themed magazines and serials, such as Ranger Rick, Owl, Chirp, Chickadee, National Geographic Kids, and Kids Discover, regularly feature poems. In fact, magazines are often the first medium in which many new poets get their work published.

\section{A poem alone is not intended to be} the entire science lesson, but poetry's brevity, conceptual focus, and carefully chosen vocabulary make it a natural teaching tool for connecting with science, whether to jump-start or introduce a topic, present examples of terminology or concepts, provide closure that is concept-rich, or extend a science topic further.

\section{Poetry Helps Address Standards}

With the growing national emphasis on STEM (science, technology, engineering, and mathematics), a multistate consortium developed the Next Generation Science Standards (NGSS) for schools across the country, offering a detailed description of the key scientific ideas and practices that all students should learn by the time they graduate from high school. There are three key dimensions of the framework-practices, concepts, and core ideas:

- Scientific and Engineering Practices (for example, asking questions, defining problems, using models, planning investigations, analyzing data, communicating information)

- Crosscutting Concepts (for example, patterns, cause and effect, scale, proportion and quantity, systems, energy and matter, structure and function, and stability and change)

- Disciplinary Core Ideas (across the physical sciences, life sciences, earth and space sciences, engineering, technology, and applications of science)

Like the Common Core State Standards, the NGSS guide us in moving from the familiar to the scientific, overlapping in their emphasis on rich discussion and critical thinking.

The NGSS emphasize knowledge retention-an area where poetry can be especially helpful by providing memorable texts filled with imagery and aural clues. Of course, a poem alone is not intended to be the entire science lesson, but poetry's brevity, conceptual focus, and carefully chosen vocabulary make it a natural teaching tool for connecting with science, whether to jump-start or introduce a topic, present examples of 


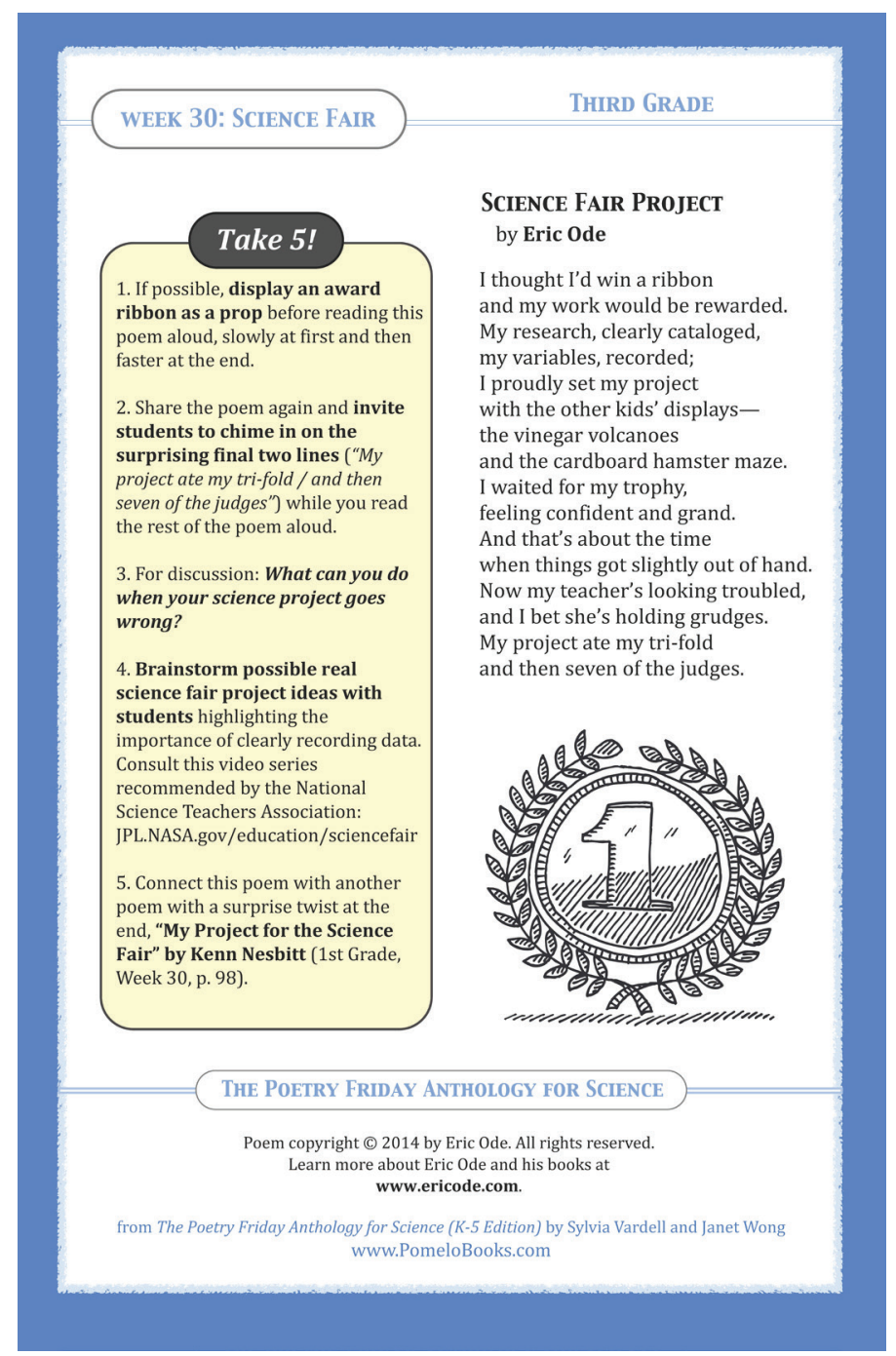

A poem from The Poetry Friday Anthology

terminology or concepts, provide closure that is concept-rich, or extend a science topic further.

\section{Look for Curriculum Connections}

While many science poems contain embedded facts, some poetry books also provide explicit curriculum connections in additional material.

- In The Poetry Friday Anthology for Science, a “Take 5!" sidebar of teaching activities or mini-lessons accompanies each of the poems to provide guidance in teaching poetry and science as well as to document which NGSS framework components are covered by each poem.

- A "Galactic Glossary" in Comets, Stars, the Moon, and Mars: Space Poems and Paintings by Douglas Florian defines everything from "the minor planets" to "the great beyond," with a sprinkling of especially kid-friendly facts.

- Face Bug by J. Patrick Lewis not only provides exceptional close-up photos of insect faces, but also ends with a section in which each of the insects featured in a poem has a firstperson statement about "Where I Live," "How I Grow," "What I Eat," and "What Eats Me." (The Pearl Crescent Butterfly says, "I count robber flies ... and, of course ... BIRDS on my Most Scary List" while the venomous Saddleback Caterpillar says, "Go away, if you know what's good for you!") ${ }^{8}$

- Nature Notes in the back of Avis Harley's poetry collection African Acrostics feature informative paragraphs alongside thumbnail photos of each of the animals highlighted in the book; Susan Blackaby provides similar information about each of the animal habitats she showcases in the poems of Nest, Nook \& Cranny. In addition, both Harley and Blackaby provide a section about the poetic forms they employ in the poems, too.

And several poets include factual prose paragraphs alongside vivid poetry to expand the learning and engagement opportunities. Look for the Newbery honor book Dark Emperor and Other Poems of the Night and others by Joyce Sidman or Bug Off? Creepy Crawly Poems among others by Jane Yolen, for example. Whether the poet incorporates information alongside the poems or in helpful back matter at the end, these extras show readers a variety of access points for learning the science content, as well as many different examples of the various forms of writing they might consider trying themselves.

\section{Develop Research Skills}

You can also use science poems to lay the groundwork for the research process or as a model for gathering and sharing key facts and vocabulary. Read widely from science, nature, or animal poems and encourage students to browse through the books and brainstorm possible topics to study. Then lead them to related nonfiction books and encourage students to identify key facts on their topic from these sources. Children can work together to create a collaborative "found" poem from a nonfiction book or a news article or encyclopedia entry as source, first underlining or highlighting what they think are the most important words in the informational passage, and then arranging those key words to create a poem.

\section{Sharing Science Poetry}

Vardell's 2013 Book Links article provides ideas for incorporating science-themed poetry into an established routine, blending science poems with activities that are already a part of the schedule. ${ }^{9}$ For example, add a poem from The Green Mother Goose: Saving the World One Rhyme at a Time edited by Jan Peck and David Davis to the usual Mother Goose program.

Pair a science-themed nonfiction or informational book such as Seymour Simon's Extreme Oceans with a picture book such as Claire Nivola's Life in the Ocean: The Story of Oceanographer 
In less than one minute, a poetry moment can promote incidental science learning, be part of science instruction, offer content-rich poetry lessons in reading and language arts_—or simply provide fun Poetry Friday sharing.

Sylvia Earle, starting the whole program with a six-line poem, "Ocean Explorer Sylvia Earle" by Leslie Bulion (from The Poetry Friday Anthology for Science), or "Dive In!" (from her book At the Sea Floor ( Cafe) to show children how writers approach the same topic in very different and distinctive ways.

In less than one minute, a poetry moment can promote incidental science learning, be part of science instruction, offer content-rich poetry lessons in reading and language arts-or simply provide fun Poetry Friday sharing.

Last summer, "Fizz, Boom, Read!"—science—was the Summer Reading Program theme in many public libraries across the country. Children participated in science-themed summer book clubs, read science-themed mysteries, and checked out science activity books. Libraries were full of science displays and activities.

Let's keep that momentum going by encouraging children's natural curiosity about how the world works and what role they might play in discovering more answers. $\&$.

\section{References}

1. Valarie L. Akerson, "Teaching Science When Your Principal Says, “Teach Language Arts,'” in Teaching Teachers: Bringing First-Rate Science to the Elementary Classroom (Arlington, VA: National Science Teachers Association Press, 2002), 22.

2. Ibid.

3. Timothy V. Rasinski, "Speed Does Matter in Reading," Reading Teacher 54, no. 10 (2000): 146-51.

4. John J. Pikulski and David J. Chard, "Fluency: Bridge Between Decoding and Reading Comprehension," Reading Teacher 58 (2005): 510-19.

5. Jill Castek, "Implementing Dynamic and Interactive Science Instruction to Meet the Common Core" (keynote speech, Regional National Science Teachers Association conference, Portland, Oregon, 2013).

6. Christine Anne Royce, Emily Morgan, and Karen Ansberry, Teaching Science Through Trade Books (Arlington, VA:
National Science Teachers Association Press, 2012), 6.

7. Erin Biba, "The Way the U.S. Teaches Science Doesn't Work: Here's How to Fix It," Popular Science 9, no. 5 (2013), www.popsci.com/science/article/2013-08/lab-session.

8. J. Patrick Lewis, Face Bug (Honesdale, PA: WordSong/ Highlights, 2013), 32-35.

9. Sylvia M. Vardell, "Classroom Connections: Connecting Science and Poetry," Book Links 4, no. 9 (2013), http://booklistonline.com/media/booklinks/ CommonCorePDFs/booklinks_ccss_2013_11_connecting -science-and-poetry.pdf.

\section{Bibliography}

Blackaby, Susan. Nest, Nook \& Cranny. Illus. by Jamie Hogan. Charlesbridge, 2010. 60p.

Bulion, Leslie. At the Sea Floor Café: Odd Ocean Critter Poems. Illus. by Leslie Evans. Peachtree, 2011. 48p

Coombs, Kate. Water Sings Blue: Ocean Poems. Illus. by Meilo So. Chronicle, 2012. 36p

Florian, Douglas. Comets, Stars, the Moon, and Mars: Space Poems and Paintings. Illustrated by the author. Harcourt, 2007.56p.

The Green Mother Goose: Saving the World One Rhyme at a Time. Ed. by Jan Peck and David Davis. Illus. by Carin Berger. Sterling, 2011. 32p.

Harley, Avis. African Acrostics: A Word in Edgeways. Illus. by Deborah Noyes. Candlewick, 2009. 40p.

Lewis, J. Patrick. Face Bug. Illus. by Frederic B. Siskind and Kelly Murphy. WordSong/Highlights, 2013. 36p.

The National Geographic Book of Animal Poetry. Ed. by J. Patrick Lewis. Illus./Photos. National Geographic, 2012. 192p.

Nivola, Claire. Life in the Ocean: The Story of Oceanographer Sylvia Earle. Illustrated by the author. Farrar, Straus and Giroux (BYR), 2012. 32p.

The Poetry Friday Anthology for Science: Poems for the School Year Integrating Science, Reading, and Language Arts. Ed. by Sylvia Vardell and Janet Wong, Pomelo Books, 2014. $308 \mathrm{p}$.

Sidman, Joyce. Dark Emperor and Other Poems of the Night. Illus. by Rick Allen. Houghton Mifflin, 2010. 32p.

Sidman, Joyce. Ubiquitous: Celebrating Nature's Survivors. Illus. by Becky Prange. Houghton Mifflin, 2010. 40p.

Simon, Seymour. Seymour Simon's Extreme Oceans. Illus./ Photos. Chronicle, 2013.60p.

Singer, Marilyn. A Strange Place to Call Home: The World's Most Dangerous Habitats and the Animals That Call Them Home. Illus. by Ed Young. Chronicle, 2012. 44p.

The Tree That Time Built: A Celebration of Nature, Science, and Imagination. Ed. by Mary Ann Hoberman and Linda Wilson. Sourcebooks, 2009. 224p.

Yolen, Jane. Bug Off! Creepy Crawly Poems. Illus. by Jason Stemple. Wordsong/Boyds Mills Press, 2012. 32p. 